\title{
Quality of Life in Women with Defecatory Dysfunctions: Systematic Review of Questionnaires Validated in the Portuguese Language
}

\section{Qualidade de vida em mulheres com disfunções defecatórias: revisão sistemática de questionários validados para a língua portuguesa}

José Ananias Vasconcelos Neto ${ }^{1}$ Camila Teixeira Moreira Vasconcelos ${ }^{2}$ Sara Arcanjo Lino Karbage ${ }^{3}$ Hérdeny Di Cárlly de Almeida Rocha Farias ${ }^{4}$ Stéffany Gadelha de Macêdo Machado ${ }^{5}$ Dayana Maia Saboia ${ }^{2}$

${ }^{1}$ Department of Urogynecology, Hospital Geral de Fortaleza, Fortaleza, CE, Brazil

2 Department of Nursing, Universidade Federal do Ceará, Fortaleza, CE, Brazil

${ }^{3}$ Department of Urogynecology, Maternidade Escola Assis Chateaubriand, Fortaleza, CE, Brazil

${ }^{4}$ Department of Urogynecology, Hospital Geral de Fortaleza, Fortaleza, CE, Brazil

${ }^{5}$ Department of Medicine, Universidade Estadual do Ceará, Fortaleza, CE, Brazil

Rev Bras Ginecol Obstet 2019;41:191-198.
Address for correspondence José Ananias Vasconcelos Neto, Departamento de Uroginecologia, Hospital Geral de Fortaleza, Rua Ávila Goulart, 900, Papicu, Fortaleza, CE, Brazil (e-mail: dr.ananiasvasconcelos@gmail.com).

\begin{abstract}
Objective To identify the quality of life (QoL) assessment instruments related to the health of women with fecal incontinence (FI) or anal incontinence (AI).

Data Sources Systematic review conducted in the Virtual Health Library (VHL), PubMed and Cochrane Library databases. The descriptors used were: Questionnaire, Questionnaires, Quality of life, validation, validation Studies, anal incontinence, fecal incontinence and constipation. The search was performed between December 26, 2017 and the beginning of January 2018. The limits used were female gender.

Selection of Studies Initially, 5,143 articles were obtained in the search. The articles of validation for Portuguese of questionnaires for the evaluation of the impact of FI/AI

Keywords

- fecal incontinence

- quality of life

- validation studies

- surveys and questionnaires

- review on the QoL of women were considered eligible.

Data Collection The article search was conducted according to the Preferred Reporting Items for Systematic Reviews and Meta-Analyzes (PRISMA) guidelines.

Data Synthesis Of the 5,143 articles, only 2 fulfilled the inclusion and exclusion criteria: Fecal Incontinence Quality of Life (FIQL) and the Wexner scale (WS). The FIQL evaluates the QoL related to $\mathrm{Fl}$, not covering flatus incontinence. The WS assesses flatus incontinence and the severity of the Al. The WS obtained an interclass correlation coefficient (ICC) of 0.932
\end{abstract}

(D)José Ananias Vasconcelos Neto ORCID is https://orcid.org/0000-0001-

6784-5970.

received

July 10, 2018

accepted

December 12, 2018

published online

March 1, 2019
DOI https://doi.org/

10.1055/s-0039-1678592.

ISSN 0100-7203.
Copyright $(2019$ by Thieme Revinter

Publicações Ltda, Rio de Janeiro, Brazil
License terms

(c) (1) 


\section{Resumo}

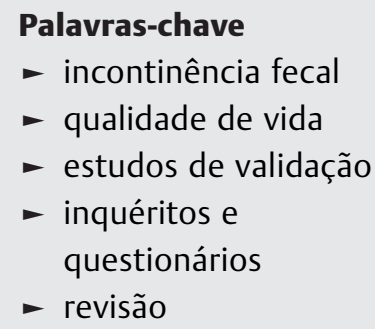

and a Cronbach $\alpha$ coefficient $>0.90$. The FIQL obtained intraexaminer and interexaminer reproducibility ranging from 0.929 to 0.957 and from 0.944 to 0.969 , respectively. Conclusions The WS and the FIQL have satisfactory reliability and validity for use during gynecological consultations.

Objetivo Identificar os instrumentos de avaliação da qualidade de vida $(\mathrm{QV})$ relacionados à saúde de mulheres com incontinência fecal (IF) ou incontinência anal (IA).

Fontes dos dados Revisão sistemática nas bases de dados da BVS, PubMed e Biblioteca Cochrane. Os descritores usados foram: Questionnaire, Questionnaires, Quality of life, validation, validation Studies, anal incontinence, fecal incontinence e constipation. A pesquisa foi realizada entre 26 de dezembro de 2017 até o início de janeiro de 2018. Os limites utilizados foram sexo feminino.

Seleção dos estudos Inicialmente, 5.143 artigos foram obtidos na pesquisa. Os artigos de validação para o português de questionários de avaliação do impacto da IF/IA na QV das mulheres foram considerados elegíveis.

Coleta de dados A busca de artigos foi conduzida de acordo com as diretrizes do Principais Itens para Relatar Revisões Sistemáticas e Meta-análises (PRISMA, na sigla em inglês).

Sínteses dos dados Dos 5.143 artigos, apenas 2 preencheram os critérios de inclusão e exclusão: Qualidade de Vida em Incontinência Fecal (FIQL, na sigla em inglês) e Escala de Wexner (WS, na sigla em inglês). O FIQL avalia a QV relacionada à FI, não abrangendo a incontinência de gases. O WS avalia a incontinência dos flatos e a gravidade da IA. O WS obteve um coeficiente de correlação interclasse (ICC, na sigla em inglês) de 0,932 e alfa de Cronbach $>0,90$. O FIQL obteve reprodutibilidade intraexaminador e interexaminador variando de 0,929 a 0,957 e de 0,944 a 0,969 , respectivamente.

Conclusões OWS e o FIQL têm confiabilidade e validade satisfatória para uso durante consultas ginecológicas.

\section{Introduction}

Anal incontinence (AI) is part of a spectrum of defecatory function disorders that also includes incomplete bowel movement, urgency, change in bowel frequency, painful defecation, and constipation. It is the most debilitating symptom of pelvic floor dysfunction (PFD), a clinical entity that encompasses fecal incontinence $(\mathrm{FI})$, urinary incontinence (UI), and pelvic organ prolapse (POP), with a greater psychosocial impact on women. ${ }^{1,2}$

In a study in which 226 women with FI were evaluated, it was observed that $35.6 \%$ of the patients had moderate to severe quality of life (QoL) impairment. ${ }^{3}$ When evaluating women with PFD, 54.6\% had defecation disorders, of which $41.4 \%$ corresponded to $\mathrm{Al}^{4}{ }^{4}$

It is estimated that the prevalence of AI in the general population can vary between 0.4 and $18 \%$, and may reach a rate of $20 \%$ in the population $>40$ years old. It is likely that these values are even greater due to the underreporting of the disease. ${ }^{3,5}$ In Brazil, 1 study found a prevalence of $7 \%$ in the adult population, with similar rates in both sexes. Regarding the type of loss, a prevalence of $3.5 \%$ was observed for fecal losses (3.1\% for men and $4.2 \%$ for women), and of $4 \%$ for gases. ${ }^{6}$

Currently, QoL assessment is used in the clinical practice, aiming to verify the impact of the disease in the life of the patient and to help in choosing the best treatment. The QoL assessment has been discussed and highlighted as an ethical, professional, and economical indicator to improve diagnosis and promote treatment efficiency. The results of the interventions have also been evaluated considering the perception of the patients of their well-being and expectations, including physical, social, emotional, and occupational aspects. ${ }^{7}$

Considering this scenario, the aim of the present study was to identify and analyze QoL questionnaires related to FI/ $\mathrm{AI}$ and constipation validated for the Portuguese language, seeking to contribute to the dissemination of these instruments in the scientific scenario and in the clinical practice and, thus, to improve knowledge and healthcare.

\section{Methods}

A systematic review was performed in the following databases: PubMed, Virtual Health Library (VHL) and Cochrane Library. The descriptors used were: Questionnaire, Questionnaires, Quality of life, validation, validation studies, anal incontinence, fecal incontinence and constipation (-Table 1).

In this search, which was performed between December 26, 2017 and the beginning of January 2018, no filters were used. The article search was conducted according to the Preferred Reporting Items for Systematic Reviews and Meta-Analyzes (PRISMA) guidelines. 
Table 1 PICO strategy

\begin{tabular}{|c|c|c|c|}
\hline & Definition & Descriptors & Limits \\
\hline Patient & Brazilian women with anal incontinence or constipation & $\begin{array}{l}\text { Anal incontinence } \\
\text { OR } \\
\text { Fecal Incontinence } \\
\text { OR } \\
\text { Constipation }\end{array}$ & Women \\
\hline \multicolumn{4}{|l|}{ AND } \\
\hline Intervention & Anal incontinence or constipation questionnaire & $\begin{array}{l}\text { Questionnaire } \\
\text { OR } \\
\text { Questionnaires }\end{array}$ & \\
\hline \multicolumn{4}{|l|}{ OR } \\
\hline Comparison & No other questionnaire or other evaluation questionnaire & & \\
\hline Outcome & Validation, reliability & $\begin{array}{l}\text { Validation } \\
\text { OR } \\
\text { Validation Studies } \\
\text { OR } \\
\text { Quality of life }\end{array}$ & \\
\hline
\end{tabular}

The articles that covered validation studies for Portuguese of QoL questionnaires related to FI/AI and constipation in women were considered eligible. Articles that did not provide the full text, duplicate articles, articles of validation of questionnaires modified for use in specific populations (patients with rectal cancer) or in patients who were opioid users were excluded. The selection of the studies was performed in three stages. In the first stage, two reviewers proceeded to read the titles of the works found. In the second stage, the abstracts of the selected articles were read. Finally, the selected articles were read in full and evaluated for the following variables:

- Identification of the publication: authorship, year of publication, journal;

- Description of the questionnaire: name of the instrument, number of questions, time spent to apply the questionnaire, and form of application of the instrument;

- Validation of the questionnaire: target population, sample, age, reliability, validity, and limitations. ${ }^{8,9}$

\section{Results}

Initially, 5,143 articles were obtained in the search. After reading the titles, 5,090 articles were excluded because they did not meet the inclusion criteria, with 53 articles being selected (-Fig. 1).

Of these, 51 were excluded after reading the abstracts according to the exclusion criteria: 17 did not assess the impact on the QoL; 3 were not FI/AI specific QoL questionnaires; 3 encompassed the pediatric population; 3 validated specific questionnaires for the population with rectal cancer or opioid users, and 25 were validated for languages other than Portuguese. Two articles, therefore, remained to be read in full. The references of the two selected articles were evaluated; however, no study was added. Finally, two validation articles for Portuguese were obtained: Wexner Scale (WS) and Fecal Incontinence Quality of Life (FIQL), ${ }^{8,9}$ the main characteristics of which are summarized in - Table 2 and - Table 3.

\section{Wexner Scale (WS)}

\section{Construction of the Questionnaire}

At the beginning of the validation process of the WS for Brazilian Portuguese, experienced native speakers and professional translators provided the first two independent translations, developing a single combined version. The first version in Portuguese, back-translated to the English language by two specialists, and the results were compared with the original instrument in American English. There was no discrepancy between the versions. Next, during a meeting with coloproctologists, urogynecologists and physiotherapists, the Brazilian Portuguese version of the WS was created.

From this, patients (70) with symptoms of AI were selected from the urogynecology outpatient clinic of a university hospital. The study took the form of an interview conducted by the researcher because many of the patients could not read or write. Out of the total sample, 5 patients were illiterate, 53 had completed elementary school, 10 had completed high school, and 1 had attended further education.

The first version of the questionnaire was tested in 20 patients with AI. To perform this test, the response "I do not understand" was included at the end of each question of the scale. The questions to which this type of response was $>15 \%$ were considered difficult to understand by this population and, therefore, were modified. Thus, the final version of the Brazilian Portuguese scale was developed.

\section{Description of the Questionnaire}

The questionnaire consists of five questions: three about AI (gas, liquid and solid), one about the loss mechanism (use of pads), and one lifestyle question (change). The score used was the same as that of the original questionnaire, and the interviewees were instructed to evaluate the frequency of fecal loss, the frequency of the use of pads, and the frequency of lifestyle changes through the use of quantifiers 


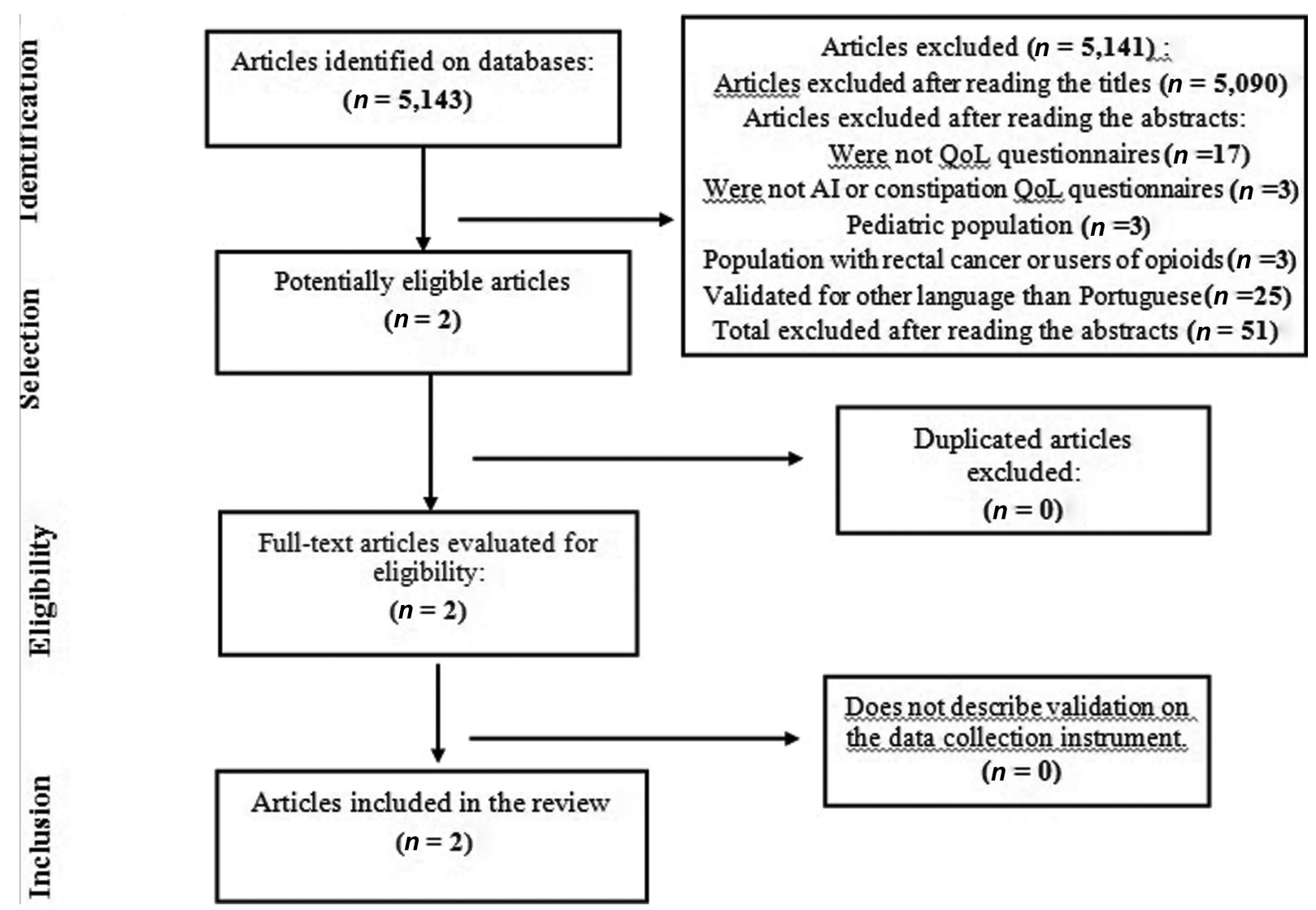

Fig. 1 Design of the PubMed, VHL and Cochrane search for articles of validation for Portuguese of quality of life questionnaires for anal incontinence and constipation.

$(0=$ never, 1 = rarely, 2 = sometimes, 3 = usually, $4=$ always). The final score was obtained through the sum of the points. Higher scores indicate greater severity of the AI. The total score in the instrument ranges from 0 (no incontinence) to 20 (complete incontinence).

\section{Validation of the Questionnaire}

After the process of translation and cultural adaptation, the WS questionnaire, already in the final Brazilian Portuguese version, along with the FIQL questionnaire, were applied in another 50 women suffering from AI. The convergent validity was assessed by comparing the data from the first WS interview with the FIQL using the Spearman correlation test.

The reproducibility (retest reliability) was evaluated over a 2-week interval, with the reapplication of the questionnaire by telephone. A total of 49 women responded to the questions. The answers of the two completed questionnaires were then analyzed.

The retest reliability was assessed using the intraclass correlation coefficient (ICC). The internal consistency was assessed using the Cronbach $\alpha$ coefficient ( - Table 4 ).

\section{Description of the Study Population}

The study population had a mean age of 57.5 years old, with the majority $(77.1 \%)$ in the postmenopausal period. The mean body mass index (BMI) was 28.7. The mean number of pregnancies was $4(0-15)$, and the mean number of vaginal deliveries was 3 (0-9). Only $10 \%$ of the patients were smokers, with no specification regarding the chronicity of the habit.

Concerning intestinal habits, 40 participants reported a regular habit, 19 reported constipation, and 11 reported diarrhea. Only $34 \%$ sought treatment for AI, and $28 \%$ reported having had been investigated by a physician about these symptoms.

The majority of these women (84.3\%) had concomitant urinary incontinence (UI). According to the patients selfreported symptoms, 23.3\% presented stress UI, 20\% urge incontinence, and $51.7 \%$ mixed incontinence.

\section{Fecal Incontinence Quality of Life (FIQL)}

\section{Construction of the Questionnaire}

The original FIQL questionnaire was translated into Brazilian Portuguese by two English teachers. The versions were compared by a multidisciplinary group composed of two physicians, one nurse, and two psychologists; and, through consensus, the first version of the questionnaire in Brazilian Portuguese was produced. This version was translated into English by two professors of American nationality. This time, the multidisciplinary group evaluated all the versions, producing the second version of the questionnaire in Brazilian Portuguese, which was used for the process of cultural adaptation.

The questionnaire was then applied in a group of 20 patients with $\mathrm{AI}$, randomly selected at the coloproctology 
Table 2 Structure of the selected validation studies: Wexner Scale and Fecal Incontinence Quality of Life questionnaire

\begin{tabular}{|c|c|c|c|c|c|c|c|}
\hline Authors & Questionnaire & $\begin{array}{l}\text { Number of } \\
\text { questions }\end{array}$ & $\begin{array}{l}\text { Items/ } \\
\text { Domains }\end{array}$ & Questions & $\begin{array}{l}\text { Score } \\
\text { variation }\end{array}$ & Time & Application \\
\hline $\begin{array}{l}\text { Fonseca et al } \\
(2016)^{8}\end{array}$ & Wexner Scale & 5 questions & $\begin{array}{l}\text { Solid } \\
\text { Liquid } \\
\text { Gas } \\
\text { Use of protectors } \\
\text { Alteration of } \\
\text { the lifestyle }\end{array}$ & $\begin{array}{l}1 \\
2 \\
3 \\
4 \\
5\end{array}$ & $\begin{array}{l}0-4 \\
0-4 \\
0-4 \\
0-4 \\
0-4\end{array}$ & Not found & Interview \\
\hline \multirow[t]{4}{*}{$\begin{array}{l}\text { Yusuf et al } \\
(2004)^{9}\end{array}$} & \multirow{4}{*}{$\begin{array}{l}\text { Fecal } \\
\text { incontinence } \\
\text { quality of } \\
\text { life (FIQL) }\end{array}$} & \multirow{4}{*}{$\begin{array}{l}4 \text { questions } \\
\text { (Total of } \\
\text { 29 items): } \\
\text { Q1: } 1 \text { item } \\
\text { Q2: } 13 \text { items } \\
\text { Q3: } 14 \text { items } \\
\text { Q4: } 1 \text { item }\end{array}$} & Lifestyle & $\begin{array}{l}10 \text { questions: Q2 } \\
\text { (items a, b, c, d, e, g, h) } \\
\text { Q3 (items b, l, m) }\end{array}$ & \multirow{4}{*}{$\begin{array}{l}1-4 \\
1-4 \\
1-4 \\
1-4 \\
1-5 \\
1-4 \\
1-6 \\
1-4 \\
1-4\end{array}$} & \multirow[t]{4}{*}{$\begin{array}{l}\text { Average time: } \\
13 \text { minutes }\end{array}$} & \multirow[t]{4}{*}{ Interview } \\
\hline & & & Behavior & $\begin{array}{l}9 \text { questions: Q2 } \\
\text { (items f, l, j, k, m) } \\
\text { Q3 (items c, h, j, n) }\end{array}$ & & & \\
\hline & & & Depression & $\begin{array}{l}7 \text { questions: Q1 } \\
\text { Q3 (items d, f, g, i, k); } \\
\text { Q4 }\end{array}$ & & & \\
\hline & & & Embarrassment & $\begin{array}{l}3 \text { questions: Q2 (Item I) } \\
\text { Q3 (items a, e) }\end{array}$ & & & \\
\hline
\end{tabular}

Abbreviations: Q1, question 1; Q2, question 2; Q3, question 3; Q4, question 4.

outpatient clinic of a university hospital. For each question in the second version of the questionnaire, the "not applicable" option was added to identify which issues would not be culturally compatible or not understood by the Brazilian population. The questions that presented $>15 \%$ of "not applicable" responses were selected and rewritten by the multidisciplinary group, trying to preserve the original concept.

Subsequently, another 20 incontinent patients were selected, in whom the third version of the questionnaire was applied, observing that no question presented a "not applicable" response $>15 \%$. Therefore, the cultural adaptation was considered complete, this being the final version of the questionnaire. The mean duration of each application was of 13 minutes.

\section{Description of the Questionnaire}

The FIQL is a specific instrument to evaluate the QoL in relation to FI. It is composed of 29 questions divided into 4 domains: lifestyle, behavior, depression, and embarrassment. The questions are scored from 1 to 4 , except for questions 1 and 4, which range from 1 to 5 and from 1 to 6 , respectively. Lower scores indicate a worse QoL.

\section{Validation of the Questionnaire}

For the performance of this stage, 50 patients with AI were selected. The reproducibility between different examiners was assessed through interviews conducted by examiners A and $B$ on the same day, with the same patient, with a 30minute interval between the interviews. Examiner A reevaluated all of the patients after a period of between 7 and 10 days to compare the results obtained by the same examiner at different times. The results obtained for intraand interexaminer reproducibility showed a significant agreement in all domains of the questionnaire. The ICCs of the evaluated domains are presented in -Table 3.

In the construct validity analysis, incontinent patients responded to the Anal Incontinence Index (AII) and to the generic questionnaire known as Short Form 36 (SF-36). The results obtained were correlated with those of the FIQL. A significant correlation was found between all FIQL and SF-36 domains (coefficient 0.754 to $0.556, p<0.01$ ), except for the pain domain (coefficient $=0.103, p=\mathrm{NS}$ ).

In the evaluation of the discriminative validity, the FIQL was applied in 30 patients with intestinal constipation and in 30 healthy volunteers. It was observed that the QoL of the AI patients was compromised in all the domains covered by the FIQL when compared with the healthy volunteers and with patients with intestinal constipation.

In the statistical analysis, the ICC, analysis of variance (ANOVA), the Pearson coefficient, and the Student $t$-test were used. The significance level established was of 0.05. Patients with more severe AI (higher indexes) had worse QoL indexes (lower values), leading to the conclusion that there was an inverse correlation between the total values of the FIQL and of the AII. In 11 cases (22\%), no correlation was observed between the FIQL values and those of the AII.

\section{Description of the Study Population}

The population was composed of incontinent patients, the majority being female (74\%). The mean age was 52.8 years old (range: 15-75 years old). Regarding the level of education, the majority (88\%) was literate. Concerning the work situation, 40 participants ( $80 \%$ ) were employed, with $12 \%$ of those unemployed attributing the cause of unemployment to the incontinence. The mean duration of the AI was of 10.2 years.

\section{Discussion}

Anal incontinence is a pathology that has a significant impact on the QoL. However, the number of instruments for its evaluation is limited. ${ }^{10-12}$ The first specific instrument for the assessment of AI was the FIQL in its original version, which was prepared in 2000 and was proposed by 
Table 3 Population and validation details of the selected validation studies: Wexner Scale and Fecal Incontinence Quality of Life questionnaire

\begin{tabular}{|c|c|c|c|}
\hline Authors & Target population & Sample & Age (mean) \\
\hline Fonseca et $\mathrm{al}^{8}$ & $\begin{array}{l}\text { Patients from the urogynecology } \\
\text { outpatient clinic }\end{array}$ & $\begin{array}{l}20 \text { patients with Al for the cultural } \\
\text { translation and adaptation } \\
50 \text { patients with Al for the } \\
\text { validation }\end{array}$ & 57.5 years old \\
\hline Yusuf et al ${ }^{9}$ & $\begin{array}{l}\text { Patients with Al from the } \\
\text { physiology of the colon, rectum, } \\
\text { and anus outpatient clinic }\end{array}$ & $\begin{array}{l}40 \text { patients with Al for the cultural } \\
\text { adaptation; } 50 \text { patients with Al for } \\
\text { the reproducibility and construct } \\
\text { validity; } 30 \text { patients with } \\
\text { constipation and } 30 \text { healthy } \\
\text { patients for the discriminative } \\
\text { validity } \\
\text { Total: } 150 \text { patients }\end{array}$ & 52.8 years old \\
\hline Authors & Reliability & Validity & Limitation \\
\hline Fonseca et $\mathrm{al}^{8}$ & Cronbachs $\alpha=0.932$ & $\begin{array}{l}\text { Convergent validity and } \\
\text { discriminant validity }\end{array}$ & $\begin{array}{l}\text { The authors did not verify whether } \\
\text { the order of application of the } \\
\text { face-to-face interview/telephone } \\
\text { interview affected the results. } \\
\text { Lack of evidence of sensitivity to } \\
\text { change. } \\
7.2 \% \text { of the patients were illiterate } \\
\text { (could be considered a bias in favor } \\
\text { of successful results.) }\end{array}$ \\
\hline Yusuf et al ${ }^{9}$ & $\begin{array}{l}\text { Intraexaminer and interexaminer } \\
\text { reproducibility ranged from } 0.929 \\
\text { to } 0.957 \text { and from } 0.944 \text { to } 0.969 \text {, } \\
\text { respectively (ICC) }\end{array}$ & $\begin{array}{l}\text { Construct validity and } \\
\text { discriminatory validity }\end{array}$ & $\begin{array}{l}\text { In } 22 \% \text { of the cases, there were no } \\
\text { results of the All corresponding to } \\
\text { the quality of life index ( } 10 \% \text { with a } \\
\text { slight impact on the quality of life } \\
\text { despite high } \mathrm{Al} / 12 \% \text { with } \\
\text { moderate or mild } \mathrm{Al} \text { ), with great } \\
\text { repercussions on } \mathrm{QL} \text { ). } \\
26 \% \text { of the population was } \\
\text { composed by men. }\end{array}$ \\
\hline
\end{tabular}

Abbreviations: Al, anal incontinence; All, anal incontinence index; ICC, intraclass correlation coefficient; QoL, quality of life.

Table 4 Internal validity of the Portuguese version of the Wexner Scale (WS) (Cronbach acoefficient) and intraclass correlation coefficients of the validation of the Fecal Incontinence Quality of Life (FIQL) questionnaire for Portuguese

\begin{tabular}{|l|l|l|}
\hline Variable (WS) & Cronbach $\alpha$ coefficient \\
\hline Solid & 0.799 \\
\hline Liquid & 0.768 \\
\hline Gas & 0.765 \\
\hline Use of protectors & 0.896 \\
\hline $\begin{array}{l}\text { Alteration of } \\
\text { the lifestyle }\end{array}$ & 0.865 & \multicolumn{2}{|l|}{} \\
\hline Total score & 0.932 & 0.944 \\
\hline Variables (FIQL) & Intraexaminer ICC & Interexaminer ICC \\
\hline Lifestyle & 0.934 & 0.973 \\
\hline Behavior & 0.938 & 0.957 \\
\hline Depression & 0.957 & 0.969 \\
\hline Embarrassment & 0.929 & \\
\hline
\end{tabular}

Abbreviation: ICC, intraclass correlation coefficient.

Source: Fonseca et al (2016) ${ }^{8}$ and Yusuf et al (2004). ${ }^{9}$
Rockwood et $\mathrm{al}^{13}$ Other instruments in the literature are: the Wexner scale (WS), the Manchester Health Questionnaire (MHQ), the Modified Manchester Health Questionnaire (MMHQ), and the Rapid Assessment Faecal Incontinence Score (RAFIS). ${ }^{8,14-16}$

Even fewer QoL instruments related to AI have been validated for Brazilian Portuguese. From the systematic review, only two instruments were found: the FIQL and the WS. ${ }^{8,9}$

The FIQL is the most widely used instrument in the international literature, validated in several different languages: French, Italian, German, Spanish, Norwegian, Turkish, Chinese, Japanese, English, and Portuguese, while the WS has only been validated in Portuguese and in Turkish. ${ }^{8,17-25}$ The FIQL evaluates the QoL of the FI patient without addressing the loss of gases, which differs from the WS. This fact is shown to be an advantageous aspect of the WS, since flatus incontinence is fairly common and is often the only manifestation of AI, which has an impact on the QoL, especially when associated with fecal loss. The addition of flatus loss to FI not only adds a negative psychological burden but can also have a significant overall impact on the general well-being of the patient. ${ }^{12}$ 
The WS consists of 5 items, 1 about lifestyle change, another about loss mechanisms, and 3 questions addressing incontinence (liquid, solid and gas), which makes its application quicker and simpler when compared with the FIQL, which has 29 items distributed in 4 domains: lifestyle, behavior, depression, and embarrassment. FIQL evaluates the QoL related to the FI patient in a more integrated way, analyzing different emotional aspects such as depression, shame, and sadness, as well as changes in daily life occurring due to the incontinence. However, it has the limitation of requiring a longer time for its application, which can make the use of the WS more attractive for research, as well as both for the researcher and for the patient, since it requires less time to be applied and is more objective, as well as being widely accepted by the scientific community. ${ }^{8,9}$

Both validations included patients with AI, with the FIQL sample being larger than that of the WS. In addition, the validation of the FIQL included patients of both genders, predominantly women (74\%), while that of the WS included only female patients. This data corroborates the fact that AI is more prevalent in females. Nelson et al (1995), ${ }^{26}$ in a study with the population of the community of an American city, reported that $2.2 \%$ of the general population had $\mathrm{AI}$, of which $63 \%$ were women. The female gender is indicated as a risk factor for AI due to pregnancy and vaginal delivery. 6,26,27

The mean age of the patients in both studies was $>50$ years old ( 57.5 years old in the WS, and 52.8 years old in the FIQL). The study by Townsend et al $(2013)^{27}$ showed that the prevalence of liquid or solid feces incontinence at least monthly increased from $9 \%$ in women aged between 62 and 64 years old to $17 \%$ in women aged between 85 and 87 years old. In a Brazilian study by Zaslavsky et al (2012), ${ }^{28}$ it was observed that people with AI have a significantly greater mean age than those without it, with the age of $>41$ years old being significantly associated with the presence of AI. ${ }^{27,28}$

According to the data obtained in the WS validation study, it was observed that $84.3 \%$ of the women had concomitant UI, which was not exposed in the validation of the FIQL. ${ }^{8}$ In 2014 , a study that evaluated symptoms of PFD found that $23.21 \%$ of the women with UI had associated $\mathrm{AI}^{4}{ }^{4}$ In another study, it was concluded that UI has a strong coexistence with FI, with $63 \%$ of the women with FI reporting UI at least monthly compared with $45 \%$ of the women of the entire study population. $^{27}$

The reproducibility of the WS was evaluated within a 2-week interval through the test-retest technique, using the ICC, which was 0.932 , demonstrating a good reliability. This was also evaluated through the Cronbach $\alpha$ coefficient, which showed a high level of internal consistency ( $\alpha>0.90)$. The FIQL validation study used only the ICC in the reliability analysis, also showing a good reproducibility. This reveals that both questionnaires have good reliability and reproducibility.

To analyze the construct validity of the FIQL, the study participants also responded to the SF-36 questionnaire and to the AII. An inverse correlation was found between the total values of the FIQL and of the AII, showing that the severity of the AI compromised the QoL. In the comparison with the SF36, a significant correlation was observed between all domains, except that of pain. On the other hand, WS used only one element for the construct validity, the FIQL, which revealed a proportionally inverse relationship between them.

The limitations of the validation study of the WS consisted of not verifying whether the order of administration of the face-to-face interview/telephone interview affected the results; not being able to recommend a different order to the one that was used; lack of evidence of sensitivity to change; and the fact that $7.2 \%$ of the patients were illiterate (which could be considered a bias in favor of successful results). During the validation of the FIQL, it was observed that $26 \%$ of the population was composed by men, and that in $22 \%$ of the cases there was no correspondence between the AI and the QoL (10\% with a slight impact on the QoL despite the high AII values, and $12 \%$ with moderate or mild AI with a high impact on the QoL). This finding was related to the sociocultural factors inherent to the individual. ${ }^{8,9}$

\section{Conclusion}

The present study showed that the QoL of the Brazilian population affected by AI can be evaluated through two validated questionnaires (the WS and the FIQL) that are widely accepted and used by the scientific community. Both questionnaires demonstrated satisfactory reliability and validity, being reliable, consistent, and valid instruments for the assessment of QoL related to AI. The WS, being shorter, can be used in the screening process for the identification of patients with FI/AI symptomatology, while the FIQL may be reserved for follow-up treatment or for comparisons in international studies.

\section{Conflicts of Interest}

The authors have no conflicts of interest to declare.

\section{References}

1 Hayden DM, Weiss EG. Fecal incontinence: etiology, evaluation, and treatment. Clin Colon Rectal Surg 2011;24(01):64-70. Doi: 10.1055/s-0031-1272825

2 Haylen BT, de Ridder D, Freeman RM, et al. An International Urogynecological Association (IUGA)/International Continence Society (ICS) joint report on the terminology for female pelvic floor dysfunction. Int Urogynecol J Pelvic Floor Dysfunct 2010;21 (01):5-26. Doi: 10.1007/s00192-009-0976-9

3 Smith TM, Menees SB, Xu X, Saad RJ, Chey WD, Fenner DE. Factors associated with quality of life among women with fecal incontinence. Int Urogynecol J Pelvic Floor Dysfunct 2013;24(03): 493-499. Doi: 10.1007/s00192-012-1889-6

4 Bezerra LR, Vasconcelos Neto JA, Vasconcelos CT, et al. Prevalence of unreported bowel symptoms in women with pelvic floor dysfunction and the impact on their quality of life. Int Urogynecol J Pelvic Floor Dysfunct 2014;25(07):927-933. Doi: 10.1007/ s00192-013-2317-2

5 Leite J, Poças F. Tratamento da incontinência fecal. Rev Port Coloproctol 2010;7:68-72

6 de Souza Santos CR, Santos VL. [Prevalence of fecal incontinence in the urban population of Pouso Alegre, Minas Gerais, Brazil]. Rev Esc Enferm USP 2011;45(01):180-186. Doi: 10.1590/S008062342011000100025

7 Ministério da Saúde. Secretaria de Ciência, Tecnologia e Insumos Estratégicos. Departamento de Ciência e Tecnologia. Diretrizes 
metodológicas: estudos de avaliação econômica de tecnologias em saúde. Brasília, DF: Ministério da Saúde; 2009

8 Fonseca AM, Meinberg MF, Lucas DV, et al. Cultural adaptation and validation of the Wexner scale in patients with anal incontinence in a Brazilian population. Int Urogynecol J Pelvic Floor Dysfunct 2016; 27(06):959-963. Doi: 10.1007/s00192-015-2927-y

9 Yusuf SA, Jorge JM, Habr-Gama A, Kiss DR, Gama Rodrigues J. Avaliação da qualidade de vida na incontinência anal: validação do questionário FIQL (Fecal Incontinence Quality of Life). Arq Gastroenterol 2004;41(03):202-208. Doi: 10.1590/S0004-28032 004000300013

10 Rama N, Passadouro R, Ferreira PL, Pimentel J. Medição da qualidade de vida em doentes com incontinência fecal. Rev Port Coloproctol 2015;12:26-31

11 Saldana Ruiz N, Kaiser AM. Fecal incontinence - Challenges and solutions. World J Gastroenterol 2017;23(01):11-24. Doi: 10.3748/wjg.v23.i1.11

12 Meyer I, Tang Y, Szychowski JM, Richter HE. The differential impact of flatal incontinence in women with anal versus fecal incontinence. Female Pelvic Med Reconstr Surg 2015;21(06): 339-342. Doi: 10.1097/SPV.0000000000000189

13 Rockwood TH, Church JM, Fleshman JW, et al. Fecal Incontinence Quality of Life Scale: quality of life instrument for patients with fecal incontinence. Dis Colon Rectum 2000;43(01):9-16, discussion 16-17. Doi: 10.1007/BF02237236

14 Bug GJ, Kiff ES, Hosker G. A new condition-specific health-related quality of life questionnaire for the assessment of women with anal incontinence. BJOG 2001;108(10):1057-1067. Doi: 10.1111/ j.1471-0528.2001.00245.x

15 Kwon S, Visco AG, Fitzgerald MP, Ye W, Whitehead WE; Pelvic Floor Disorders Network (PFDN). Validity and reliability of the Modified Manchester Health Questionnaire in assessing patients with fecal incontinence. Dis Colon Rectum 2005;48(02):323-331, discussion 331-334. Doi: 10.1007/s10350-004-0899-y

16 de la Portilla F, Calero-Lillo A, Jiménez-Rodríguez RM, et al. Validation of a new scoring system: Rapid assessment faecal incontinence score. World J Gastrointest Surg 2015;7(09): 203-207. Doi: 10.4240/wjgs.v7.i9.203

17 Altomare DF, Rinaldi M, Giardiello GG, et al. [Italian translation and prospective validation of fecal incontinence quality of life (FIQL) index]. Chir Ital 2005;57(02):153-158
18 Ahnis A, Holzhausen M, Rockwood TH, Rosemeier HP. FLQAI - A Questionnaire on Quality of Life in Fecal Incontinence: German translation and validation of Rockwood et al.'s (2000) Fecal Incontinence Quality of Life Scale (FIQLS). Z Gastroenterol 2012;50(07):661-669. Doi: 10.1055/s-0031-1299318

19 Dedeli O, Fadiloglu C, Bor S. Validity and reliability of a Turkish version of the Fecal Incontinence Quality of Life Scale. J Wound Ostomy Continence Nurs 2009;36(05):532-538. Doi: 10.1097/ WON.0b013e3181b36010

20 Dehli T, Martinussen M, Mevik K, et al. Translation and validation of the Norwegian version of the fecal incontinence quality-of-life scale. Scand J Surg 2011;100(03):190-195. Doi: 10.1177/1457496 91110000310

21 Mak TW, Leung WW, Ngo DK, Lee JF, Hon SS, Ng SS. Translation and validation of the traditional Chinese version of the faecal incontinence quality of life scale. Int J Colorectal Dis 2016;31(02): 445-450. Doi: 10.1007/s00384-015-2462-9

22 Minguez M, Garrigues V, Soria MJ, Andreu M, Mearin F, Clave P. Adaptation to Spanish language and validation of the fecal incontinence quality of life scale. Dis Colon Rectum 2006;49 (04):490-499. Doi: 10.1007/s10350-006-0514-5

23 Rullier E, Zerbib F, Marrel A, Amouretti M, Lehur PA. Validation of the French version of the Fecal Incontinence Quality-of-Life (FIQL) scale. Gastroenterol Clin Biol 2004;28(6-7 Pt 1):562-568. Doi: 10.1016/S0399-8320(04)95012-9

24 Tsunoda A, Yamada K, Kano N, Takano M. Translation and validation of the Japanese version of the fecal incontinence quality of life scale. Surg Today 2013;43(10):1103-1108. Doi: 10.1007/s00595-012-0412-5

25 Cam C, Selcuk S, Asoglu MR, et al. Validation of the Wexner scale in women with fecal incontinence in a Turkish population. Int Urogynecol J Pelvic Floor Dysfunct 2011;22(11):1375-1379. Doi: 10.1007/s00192-011-1464-6

26 Nelson R, Norton N, Cautley E, Furner S. Community-based prevalence of anal incontinence. JAMA 1995;274(07):559-561. Doi: 10.1001/jama.1995.03530070057030

27 Townsend MK, Matthews CA, Whitehead WE, Grodstein F. Risk factors for fecal incontinence in older women. Am J Gastroenterol 2013;108(01):113-119. Doi: 10.1038/ajg.2012.364

28 Zaslavsky C, Jurach MT, Barros CP, et al. Epidemiologia da incontinência anal em população assistida em serviços de saúde de Porto Alegre/RS, Brasil. Rev AMRIGS 2012;56:289-294 